\title{
Fatigue crack growth in notched specimens: a numerical analysis
}

\author{
F.V. Antunes, R. Branco, P. Prates, J.D.M. Costa \\ University of Coimbra, Portugal \\ fernando.ventura@dem.uc.pt,http:/ /orcid.org/0000-0002-0336-4729 \\ ricardo.branco@dem.uc.pt, bttp://orcid.org/0000-0001-2345-6789 \\ pedro.prates@dem.uc.pt,http://orcid.org/0000-0001-2345-6789 \\ jose.domingos@dem.uc.pt
}

\begin{abstract}
Fatigue crack growth (FCG) is linked to irreversible and nonlinear processes happening at the crack tip, which explains different problems observed in the use of $\mathrm{da} / \mathrm{dN}-\Delta \mathrm{K}$ curves. The replacement of $\Delta \mathrm{K}$ by nonlinear crack tip parameters, namely the crack tip opening displacement (CTOD) is an interesting alternative. The objective in here is to study the effect of notches on FCG using the plastic CTOD range, $\delta_{\mathrm{p}}$. M(T) specimens with lateral notches of different radius $(1,2,4$ and $8 \mathrm{~mm}$ were analysed numerically, keeping the total depth constant $(8 \mathrm{~mm})$. The increase of crack length increases $\delta_{\mathrm{p}}$ and therefore FCG rate. For plane stress state, the formation of the residual plastic wake with crack propagation, produces crack closure which compensates the effect of crack length and there is a stabilization of $\delta_{\mathrm{p}}$. The reduction of notch radius increases $\delta_{\mathrm{p}}$ for all crack lengths, particularly for the shortest ones. For plane strain state there is almost no crack closure therefore $\delta_{\mathrm{p}}$ is higher than for plane stress state, and the effect of crack length produces a relatively fast increase of $\delta_{\mathrm{p}}$.
\end{abstract}

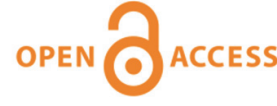

Citation: Antunes, V. V., Branco, R., Prates, P., Costa J.D.M., Fatigue crack growth in notched specimens: a numerical analysis, Frattura ed Integrità Strutturale, 48 (2019) 666-675.

Received: 18.09 .2018

Accepted: 11.11 .2018

Published: 01.01.2019

Copyright: (C) 2019 This is an open access article under the terms of the CC-BY 4.0, which permits unrestricted use, distribution, and reproduction in any medium, provided the original author and source are credited.

KEYwORDS. Fatigue crack growth; Notches; Plastic CTOD; Crack closure.

\section{INTRODUCTION}

$\mathrm{T}$ he study of fatigue crack propagation is usually based on relations between the crack increment per load cycle, $\mathrm{da} / \mathrm{dN}$, and the stress intensity factor range, $\Delta \mathrm{K}$. [1]. The $\mathrm{dN}-\Delta \mathrm{K}$ relationship is supposed to be invariant relatively to the shape and size of the cracked component. $\Delta \mathrm{K}$ is a linear elastic parameter, however it controls the small-scale cyclic plastic deformation occurring at the crack tip [2]. Nevertheless, da/dN- $\Delta \mathrm{K}$ relations have several limitations, namely: (i) such curves are completely phenomenological, not derived from physics, and the fitting parameters have units with no physical justification; (ii) such curves are only valid in the small-scale yielding range; (iii) and da/dN depends on other parameters, including the stress ratio and the load history.

Different concepts have been proposed to overcome the limitations identified in the use of $\mathrm{dN}-\Delta \mathrm{K}$ relationships, which are effectively caused by using a linear elastic parameter to quantify the non-linear irreversible processes responsible for 
fatigue crack growth (FCG). Crack closure was proposed [3] and has been used as a complementary parameter to explain the effect of plastic deformation on FCG relations. It has been used to explain the effects of stress ratio, overloads, short cracks and specimen thickness. The T-stress is another concept which has been used to explain the effect of specimen geometry [4]. The concept of partial crack closure, proposed by Donald and Paris [5] and Kujawski [6], assumes that the contact of crack flanks does not occur immediately behind crack tip and there is, therefore, a contribution of the load range below crack opening to fatigue damage. Christopher et al. [7] proposed a new model based on four parameters to describe the stresses around the crack tip: $K_{F}$ (opening mode stress intensity factor), $K_{S}$ (shear stress intensity factor), $K_{R}$ (retardation stress intensity factor) and the T-stress. However, these new concepts only mitigate the problem, without attacking the real source of the problem. In authors' opinion, the linear elastic $\Delta \mathrm{K}$ parameter must be replaced by nonlinear crack tip parameters, able to quantify effectively the crack tip plastic deformation which is supposed to control fatigue crack growth rate (FCGR). The effect of physical parameters like thickness, stress state, specimen geometry and/or overloads is naturally accommodated by the non-linear parameters. Antunes et al. [8] used non-linear parameters to validate the crack closure concept and to identify the best crack closure parameter. The non-linear parameters identified in the literature review made by Antunes et al. [8] were the range of cyclic plastic strain, the size of reversed plastic zone, the total plastic dissipation per cycle and the crack opening displacement. Note that these non-linear crack tip parameters, and also the $\mathrm{J}$ integral, usually replace $\mathrm{K}$ when the LEFM is no longer valid.

The crack opening displacement (COD) is a classical parameter in elastic-plastic fracture mechanics, still widely used nowadays [9]. It has a direct physical meaning and can be measured experimentally. Crack tip blunting and re-sharpening has been used to explain fatigue crack propagation under cyclic loading [10]. This cyclic blunting and re-sharpening was modeled by different authors in order to predict the FCGR [11]. Additionally, it was demonstrated that there is a relationship between COD and striation spacing, and between this and the crack propagation rate [12]. The experimental measurement of COD has been done using different strategies. In Compact-Tension (CT) specimens, an extensometer with blades is used to measure the opening of the specimen at the edge. Therefore, this parameter is usually called crack mouth opening displacement (CMOD). In Middle-Tension $(\mathrm{M}(\mathrm{T})$ ) specimens, a pin extensometer is placed at the center of the specimen, fixed in two small holes to avoid sliding. The resulting force versus displacement curves are typically used to calculate the crack closure level. Digital Image Correlation (DIC) has been used to define a virtual extensometer, therefore COD can be obtained at different positions relatively to the crack tip. However, analytical or numerical approaches are required to measure the crack tip opening displacement, CTOD. In the finite element method (FEM) studies the CTOD is usually measured at the first node behind crack tip.

The use of CTOD in the study of FCG in notched samples has not been seen in literature. One of the well-known approaches to deal with the notch effect in fatigue problems was proposed by Neuber [13] who stated that the geometric mean value of the stress concentration factor and strain concentration factor is constant and equal to the elastic stress concentration factor. Glinka [14] developed an energy-based approach, known as equivalent strain energy density, based on the assumption that the elastic-plastic strain energy density of the material in the yielded zone of the material is equal to the strain energy density assuming an elastic behaviour. Other current and important energy-based approaches are, for example, the control-volume technique introduced by Lazzarin [15] and the total strain energy density concept formulated by Ellyin [16]. It should be also mentioned the Theory of Critical Distances which combines a set of alternative approaches which have in common the fact that the effective stresses at the process zone is estimated on the basis of a characteristic material length, also called critical distance [17-19]. However, these methodologies have some limitations.

The main objective here is to study numerically the effect of notches on fatigue crack growth rate using the plastic CTOD concept recently introduced by Antunes et al. [20]. The material studied was the 7050-T6 aluminium alloy, in the form of Single-Edge Notch Tension specimens (SENT). The radius of the notch was varied, keeping constant the total depth of the notch. An automatic elastic-plastic finite-element procedure was developed and the simulations were computed assuming both plane stress and plane strain conditions.

\section{NUMERICAL MODEL}

$\mathrm{F}$ ig. 1a shows the geometry of the notched samples. Four different notches were considered, with radius of $8,4,2$ and $1 \mathrm{~mm}$, as illustrated by Figs. 1c, 1d, 1e and 1f, respectively. The total notch depth was always $8 \mathrm{~mm}$, as indicated. The initial crack length was $a_{0}=8.096 \mathrm{~mm}$ including the notch, i.e., the initial crack extended $96 \mu \mathrm{m}$ ahead of the notch. The specimens had a thickness of $0.2 \mathrm{~mm}$ in order to simulate pure plane stress state. Additionally, plane strain state was modeled imposing boundary conditions which avoid out-of-plane plane deformation. Only $1 / 4$ of the 
specimen was modeled considering adequate boundary conditions, as indicated in Fig. 1a. A cyclic load was applied remotely from crack tip, as illustrated in Fig. 1a, with $F_{\max }=400 \mathrm{~N} ; \mathrm{F}_{\min }=4 \mathrm{~N}(\mathrm{R}=0.01)$.

The material studied was the 7050-T6 aluminum alloy, which is strengthened mainly by the addition of $\mathrm{Zn}, \mathrm{Mg}$ and $\mathrm{Cu}$. The T6 heat treatment comprises homogenization and aging, producing hardening by precipitation. The AA7050-T6 has excellent properties, namely good fracture toughness, high strength and stress corrosion resistance, making it ideal for applications in aircraft industry [21, 22]. Cyclic stress-strain hysteresis loops, obtained in smooth samples, were used to fit the hardening models. The elastic-plastic model adopted assumes that the plastic behavior follows the von Mises yield criterion, coupled with Voce isotropic hardening law [23]:

$$
\mathrm{Y}\left(\bar{\varepsilon}^{p}\right)=\mathrm{Y}_{0}+\left(\mathrm{Y}_{\mathrm{Sat}}-\mathrm{Y}_{0}\right)\left[1-\exp \left(-\mathrm{C}_{Y} \bar{\varepsilon}^{p}\right)\right]
$$

where $\mathrm{Y}_{0}, \mathrm{Y}_{\mathrm{Sat}}$ and $\mathrm{C}_{\mathrm{Y}}$ are material parameters and $\bar{\varepsilon}^{p}$ is the equivalent plastic strain, and Lemaitre-Chaboche non-linear kinematic hardening law [24]:

$$
\dot{\mathbf{X}}=C_{\mathrm{X}}\left[X_{\mathrm{Sat}} \frac{\sigma^{\prime}-\mathbf{X}}{\bar{\sigma}}-\mathbf{X}\right] \dot{\bar{\varepsilon}}^{\mathrm{p}}
$$

being $\mathrm{C}_{\mathrm{x}}$, and $\mathrm{X}_{\text {sat }}$ material parameters. Table 1 shows the identified set of material parameters of Voce and LemaitreChaboche laws. Fig. 1 compares experimental results with the analytical model proposed here. Several load cycles were applied and the cumulative plastic strain is plotted versus stress. An excellent agreement can be seen, indicating that the analytical model is able to simulate the cyclic plastic deformation.

Voce law parameters

Lemaitre-Chaboche law parameters

\begin{tabular}{ccccc}
\hline $\mathrm{Y}_{0}$ & $\mathrm{C}_{\mathrm{Y}}$ & $\mathrm{C}_{\mathrm{x}}$ & $\mathrm{X}_{\text {sat }}$ \\
{$[\mathrm{MPa}]$} & $\begin{array}{r}\mathrm{MPa}] \\
420.50\end{array}$ & 3.806 & 228.91 & 198.35 \\
\hline
\end{tabular}

Table 1: Material parameters for the 7050-T6 aluminum alloy.

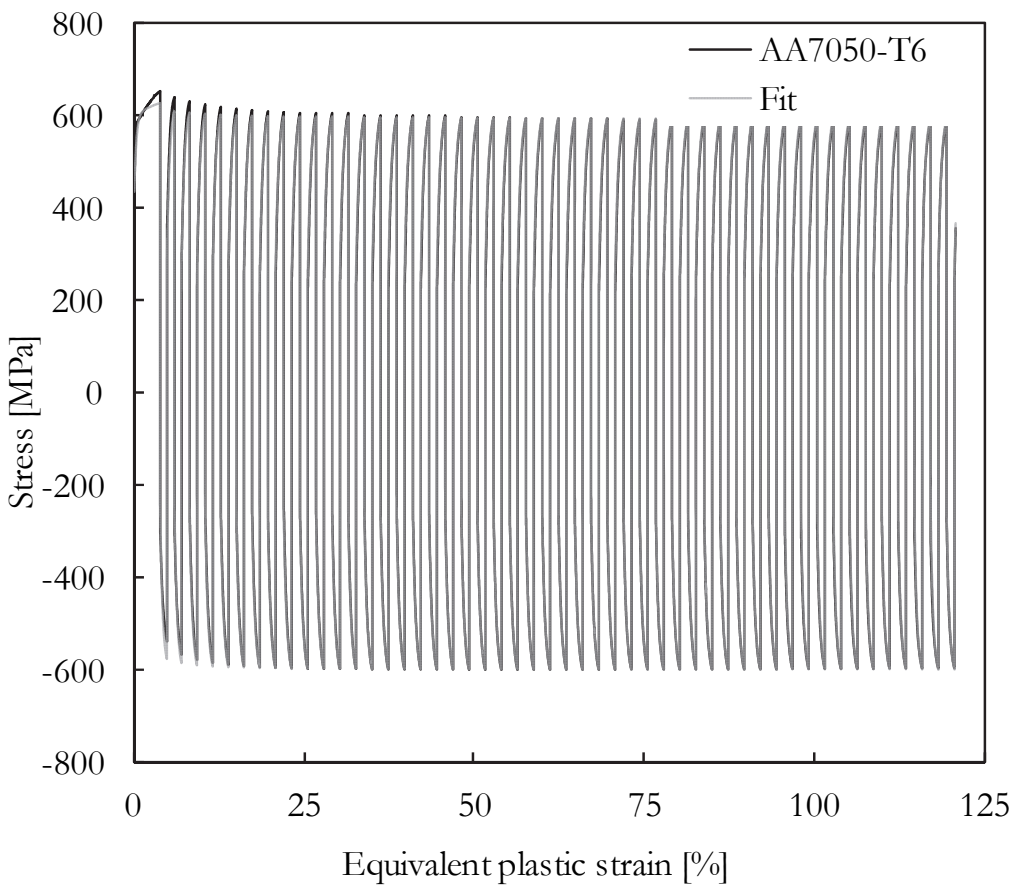

Figure 1: Accuracy of material's model: experimental results versus analytical model. 
The finite element mesh illustrated in Fig. 2, composed of 3D linear isoparametric elements, has 7175 elements and 7359 nodes. As can be seen in Fig. 1b, a refined mesh was defined near the notch, where the elements have $8 \times 8 \mu \mathrm{m}^{2}$. The crack was extended at minimum load, after each two load cycles. The total crack propagation was $159 \times 8=1272 \mu \mathrm{m}$.

\section{RESULTS}

\section{Distribution of stresses ahead of notch}

7 ig. 3 presents the distribution of linear elastic stresses ahead of notch for the different notch radius, $\mathrm{R}_{\mathrm{n}}$. These stresses were divided by the remote stress. The stresses are higher for the lower values of $R_{n}$, as could be expected. For plane stress state there is a turning point at about $1.5 \mathrm{~mm}$, while for the plane strain state this turning point is at about $1 \mathrm{~mm}$. In fact, the comparison of Figs. $2 \mathrm{a}$ and $\mathrm{b}$ indicates that for plane strain state the variation of stresses with distance from the notch is much faster. The stress concentration factors, obtained dividing the local stresses by the remote stress, are presented in table 2 . The decrease of stress ratio increases $\mathrm{K}_{\mathrm{t}}$, and the plane strain state promotes higher values of $\mathrm{K}_{\mathrm{t}}$ than the plane stress state. There is an exception for plane stress state, because the notch ratio of $1 \mathrm{~mm}$ gave slightly lower $\mathrm{K}_{\mathrm{t}}$ than $\mathrm{R}_{\mathrm{n}}=2 \mathrm{~mm}$.

\begin{tabular}{ccc}
\hline $\mathrm{R}_{\mathrm{n}}[\mathrm{mm}]$ & $\mathrm{K}_{\mathrm{t}}$ (Plane stress) & $\mathrm{K}_{\mathrm{t}}$ (Plane strain) \\
1 & 3.64 & 3.99 \\
2 & 3.70 & 3.77 \\
3 & 3.59 & 3.52 \\
4 & 3.26 & 3.05 \\
\hline
\end{tabular}

Table 2: Stress concentration factors.
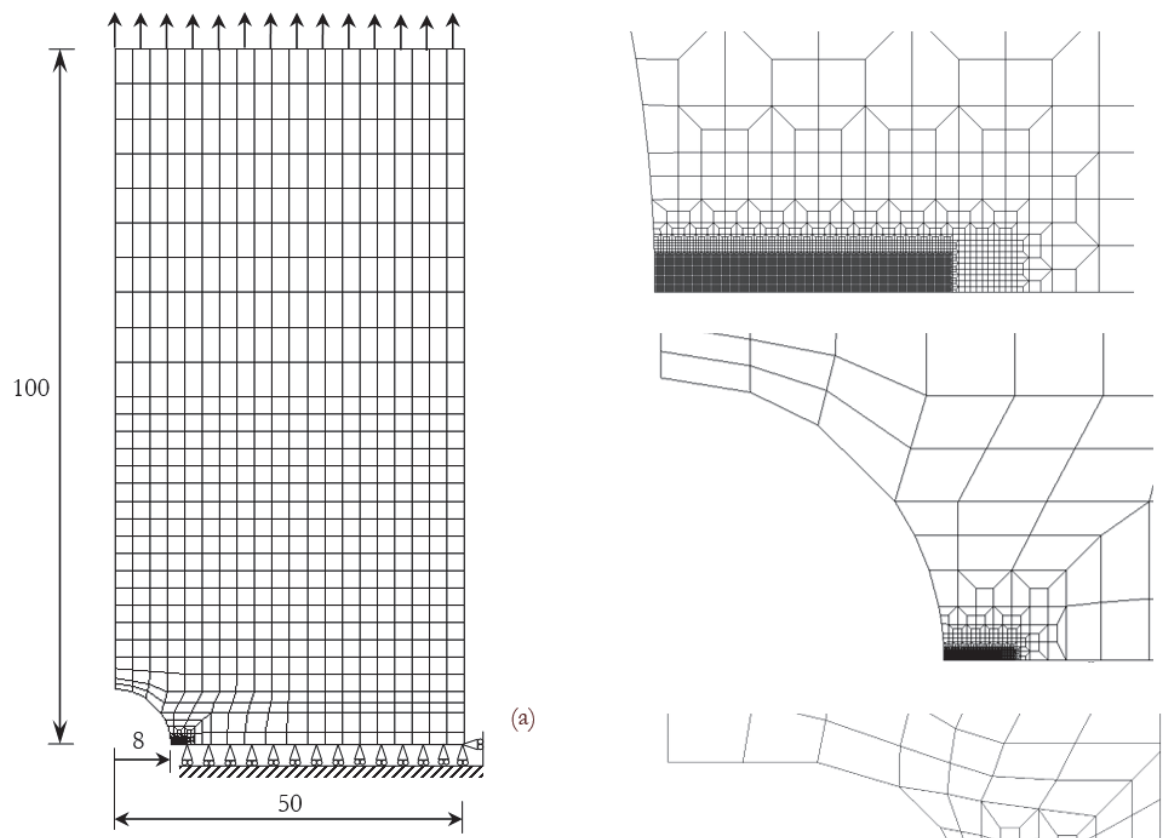

(b)

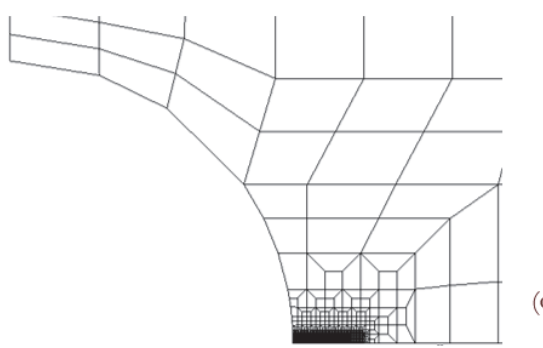

(a)
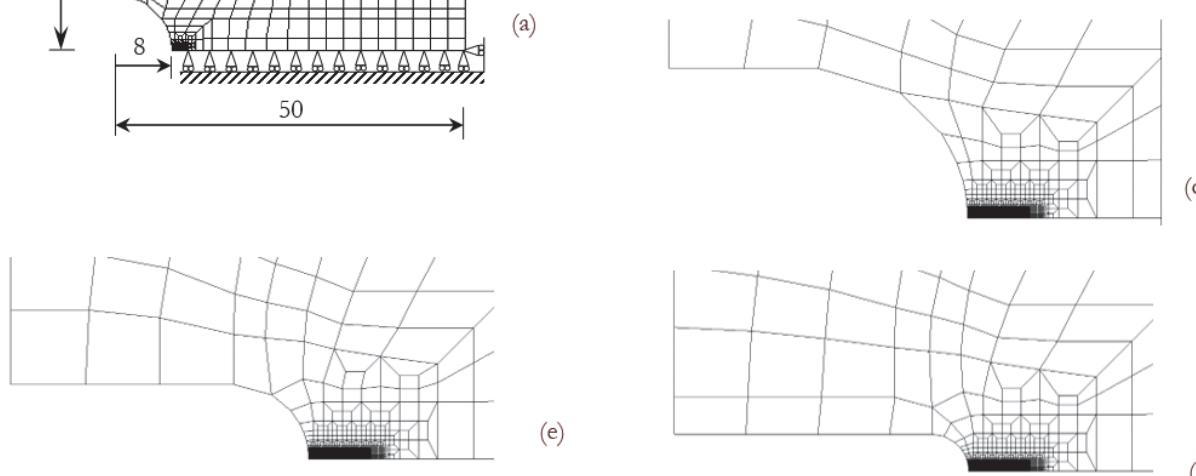

Figure 2: Geometry and finite element mesh of the notched samples. (a) Loading and boundary conditions. (b) Detail of finite element mesh. (c) Notch radius of $8 \mathrm{~mm}$. (d) Notch radius of $4 \mathrm{~mm}$. (e) Notch radius of $2 \mathrm{~mm}$. (f) Notch radius of $1 \mathrm{~mm}$. 

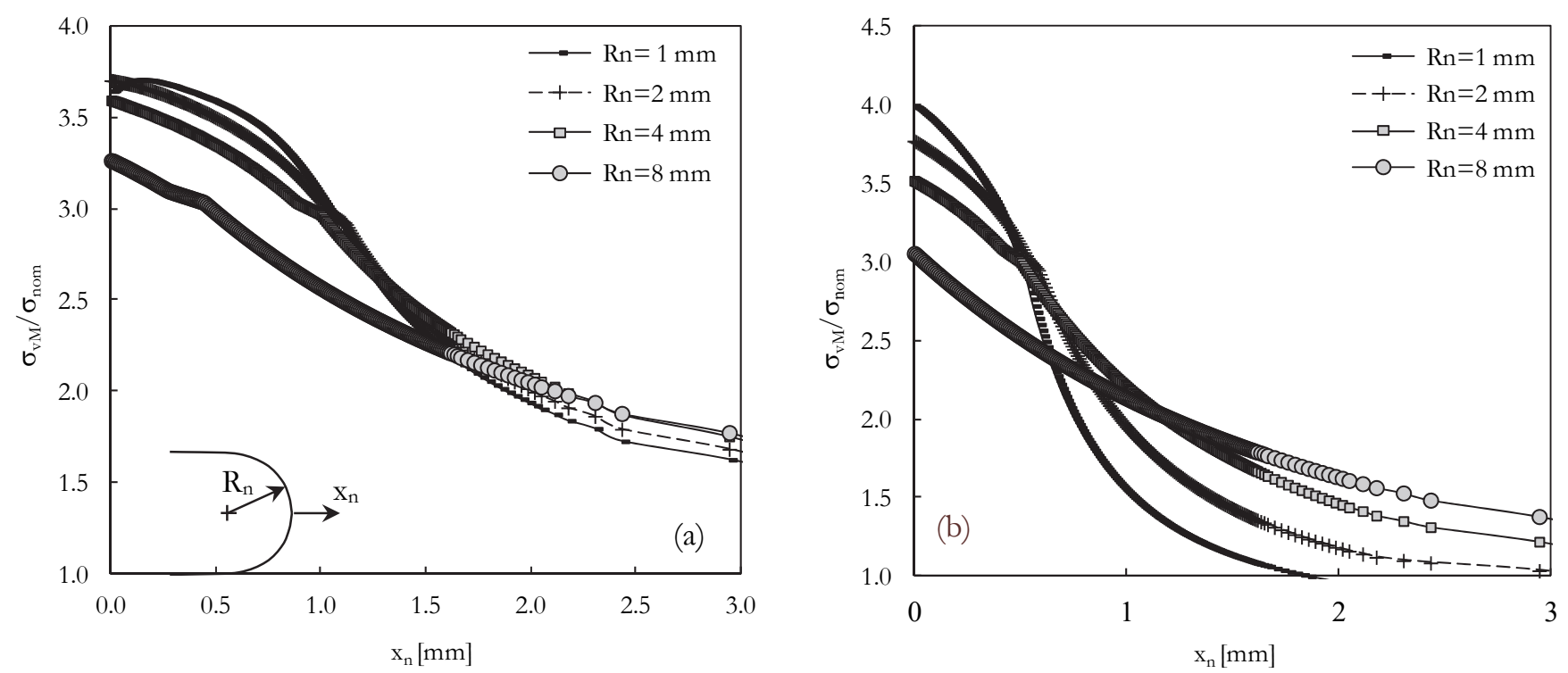

Figure 3: Distribution of von Mises equivalent stress ahead of the notch (uncracked geometry; elastic behavior). (a) Plane stress state. (b) Plane strain state.

\section{Plastic CTOD range}

Figs. $4 \mathrm{a}$ and $4 \mathrm{~b}$ present typical results of CTOD versus load, measured for crack increments of 40 and $800 \mu \mathrm{m}$, respectively. The first node behind crack tip is closed at minimum load and only opens when the load reaches point A (Fig. 4b), which is the crack opening load. After opening the CTOD increases linearly with load, but after point B there is some deviation from linearity which indicates the occurrence of plastic deformation. The maximum CTOD occurs at point $\mathrm{C}$, which corresponds to the maximum applied load. After the maximum load there is also a linear variation of CTOD with load decrease. With subsequent load decrease, reversed plastic deformation starts and the crack closes again. The plastic deformation increases progressively for loads above point $\mathrm{B}$, up the maximum load. The plastic CTOD was obtained subtracting the elastic CTOD from the total CTOD. The comparison of both figures indicates that the crack increment increases the crack closure level, which is logical because the plastic wake increases. The slope of linear regime increases because the rigidity of the specimen reduces with crack growth. Although the increase of crack closure, the crack growth increases the plastic CTOD range, which results from the effect of crack length on crack tip stresses.
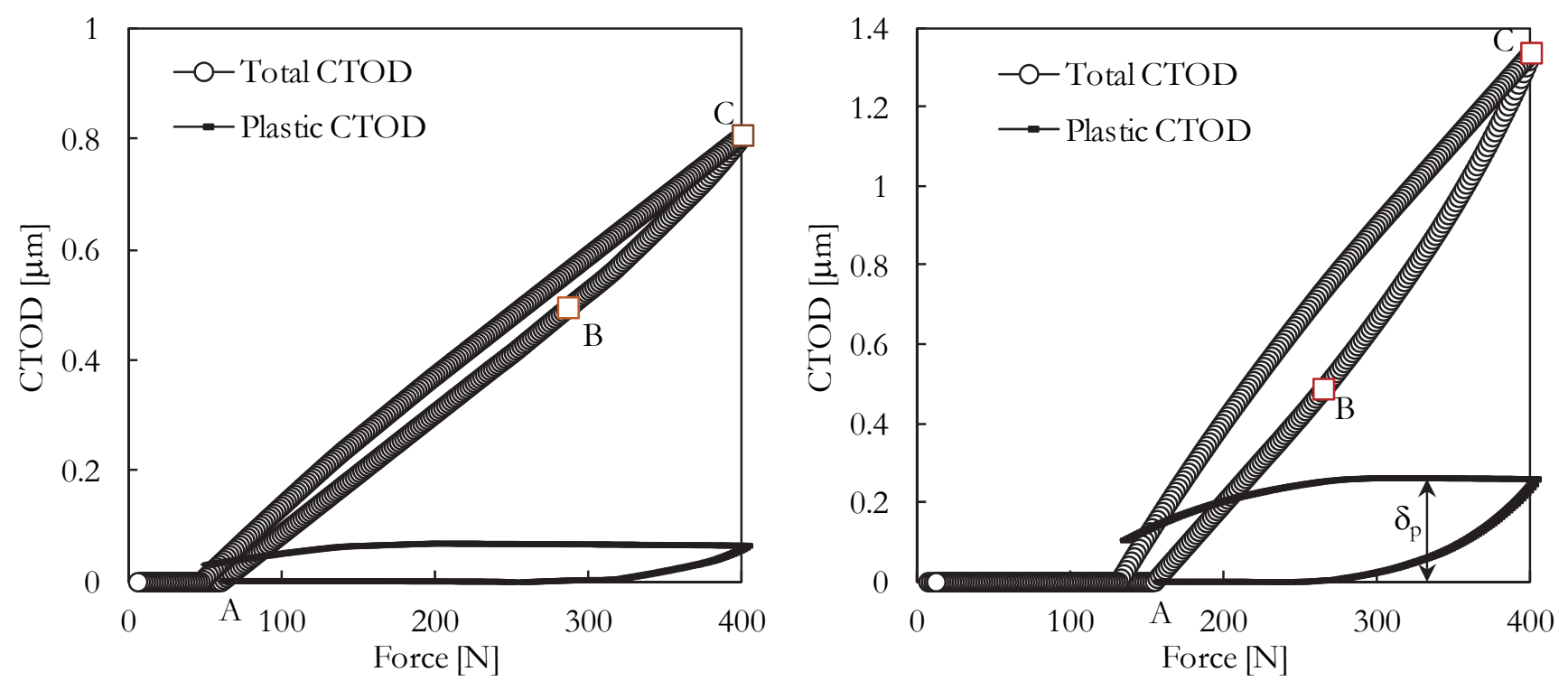

Figure 4: Crack tip opening displacement (plane stress, $\mathrm{R}_{\mathrm{n}}=4 \mathrm{~mm}$ ). (a) $\Delta \mathrm{a}=40 \mu \mathrm{m}$. (b) $\Delta \mathrm{a}=800 \mu \mathrm{m}$. 
Fig. 5 presents the variation of plastic CTOD range, $\delta_{\mathrm{p}}$, with crack growth for different notch radius. The increase of crack length tends to increase $\delta_{\mathrm{p}}$ and therefore fatigue crack growth rate. However, for notch radius of 1 and $2 \mathrm{~mm}$, there is a rapid decrease of $\delta_{\mathrm{p}}$ at the beginning of crack growth, followed by a progressive increase. The progressive increase of $\delta_{\mathrm{p}}$ with notch radius, $\mathrm{R}_{\mathrm{n}}$, is steeper for plane strain state. For plane stress state, a convergence to the same value is evident, as the crack departs from the notch. This asymptote is expected to be the value of $\delta_{\mathrm{p}}$ not affected by the notch. For plane strain state, this convergence is not so evident, which seems to indicate that the effect of the notch is more extensive. The decrease of notch radius increases $\delta_{\mathrm{p}}$, due to the increase of stresses.
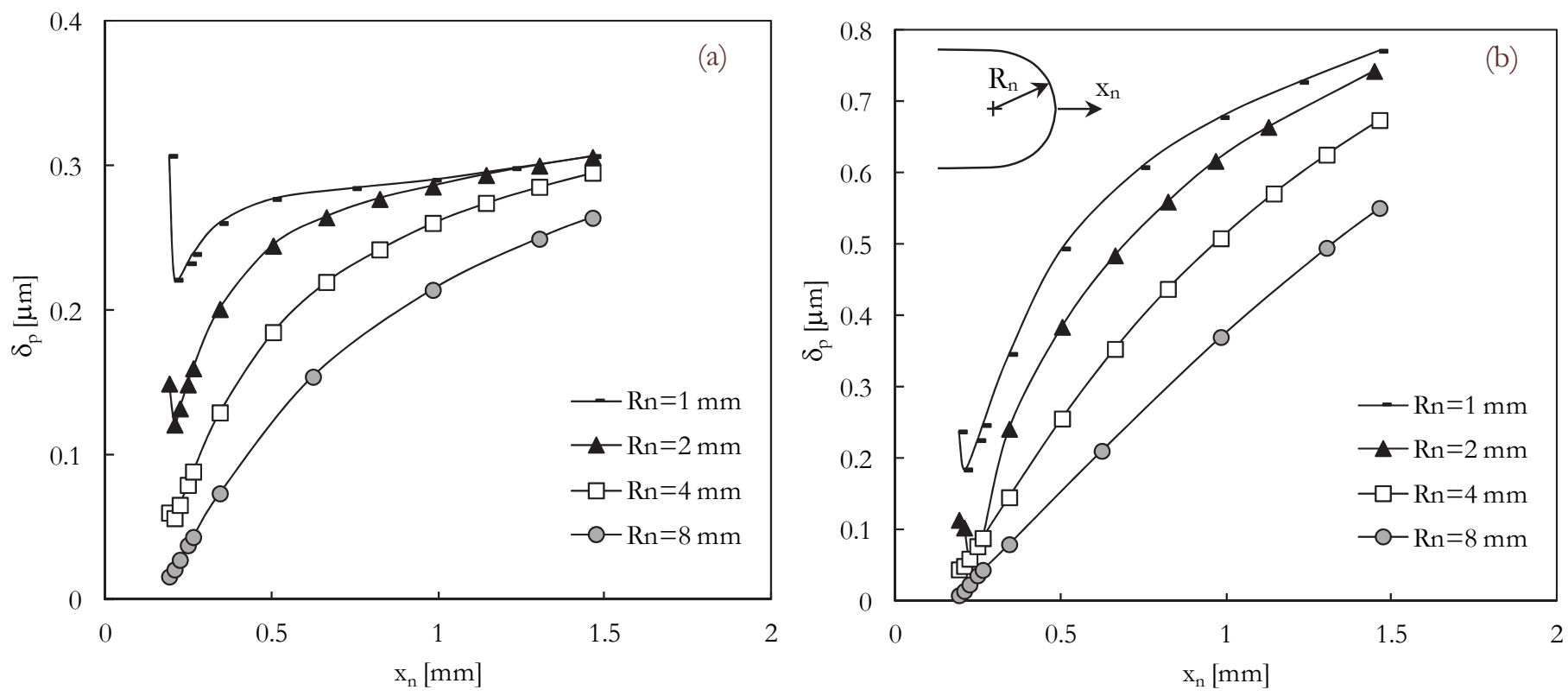

Figure 5: Variation of plastic CTOD range with crack growth. (a) Plane stress state. (b) Plane strain state.

Fig. 6 presents the effect of stress state for different notch radius. At the beginning of crack growth plane stress state gives higher values of $\delta_{\mathrm{p}}$. However, rapidly the values for plane strain state raise above those for plane stress state, and become significantly higher. The higher crack growth rate observed for plane strain state explains the curvature of crack fronts in through-cracked specimens.

Fig. 6 shows the variation of crack closure level, quantified by:

$$
\mathrm{U}_{\text {clos }}=\frac{\mathrm{F}_{\text {open }}-\mathrm{F}_{\text {min }}}{\mathrm{F}_{\text {max }}-\mathrm{F}_{\text {min }}} \times 100
$$

being $F_{\min }, F_{\max }$ and $F_{o p e n}$ the minimum, maximum and opening loads, respectively. This parameter quantifies the portion of load cycle during which the crack is closed. The plane stress predictions are clearly higher than plane strain results. For plane strain state and notch radius of 1 and $2 \mathrm{~mm}$, there is an initial peak of $\mathrm{U}_{\text {clos }}$ followed by a progressive stabilization. This peak is linked to an odd deformation produced by the first load cycle. All the curves converge rapidly to about $\mathrm{U}_{\mathrm{clos}}=10 \%$.For plane stress state there is a progressive increase of crack closure with crack length, as the plastic wake is being formed. The decrease of notch radius increases $\mathrm{U}_{\text {clos, }}$ which has a faster stabilization.

The results in Fig. 5 are explained by the relatively low level of crack closure observed for plane strain state. The trends of Fig. 4 are also explained by crack closure. For plane stress state there is a faster stabilization of $\delta_{\mathrm{p}}$ for shorter notch radius because the crack closure level increases more rapidly. The crack closure is responsible for the convergence of all the curves. For plane strain state, the crack closure level is relatively low, therefore the increase of crack length if felt more intensively on $\delta_{\mathrm{p}}$. 

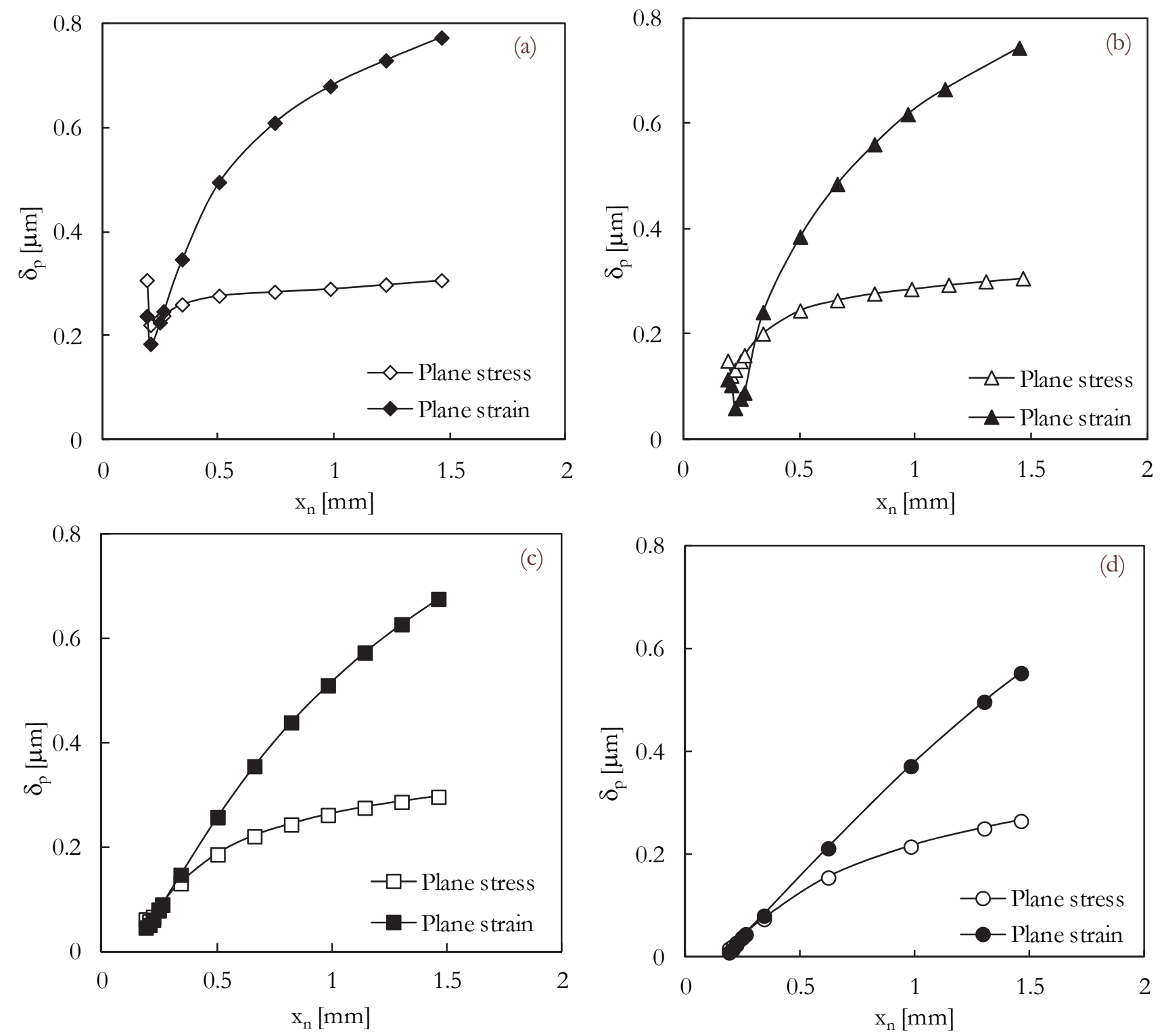

Figure 6: Variation of plastic CTOD range with crack growth (a) $R_{n}=1 \mathrm{~mm}$. (b) $R_{n}=2 \mathrm{~mm}$. (c) $R_{n}=4 \mathrm{~mm}$. (d) $R_{n}=8 \mathrm{~mm}$.

\section{Discussion}

7 he present study involves two topics of major relevance for FCG, which are notches and short cracks. For short crack, the hypothesis of small-scale yielding may be violated, therefore the use of plastic CTOD instead of $\Delta \mathrm{K}$ is of major importance. The stress concentration associated with the notch reinforces this need. In fact, Miller [25] suggested the use of elastic-plastic fracture mechanics to analyse short fatigue crack growth.

The increase of crack length produces several effects:

- the increase of the distance to the notch and consequent reduction of stress concentration.

- the increase of crack length and, therefore, of crack tip stresses and $\delta_{\mathrm{p}}$.

- the increase of crack closure as the plastic wake is formed. This is more relevant for plane stress state. It reduces the effective load range and therefore $\delta_{\mathrm{p}}$. The crack closure concept is widely used to explain the short crack behaviour $[26,27]$. 
The variation of crack length is the cause of the global trend for the increase of $\delta_{\mathrm{p}}$ with crack growth. For plane stress state, the increase of crack length is accomplished by an increase of crack closure which stabilizes the values of $\delta_{\mathrm{p}}$. In other words, the effect of crack length is compensated by the increase of crack closure. The decrease of notch radius produces a faster increase of crack closure and therefore a faster stabilization of $\delta_{\mathrm{p}}$. For plane strain state, there is almost no crack closure, therefore $\delta_{\mathrm{p}}$ is bigger than for plane stress state. The absence of crack closure produces a faster growth of $\delta_{\mathrm{p}}$ with crack propagation, explained by the increase of crack length and by the progressive separation from the notch. Ding et al. [28] studied the 1070 steel in the form of round bars and concluded that for positive stress ratios FCG is mainly influence by notch plasticity, while for negative stress ratios crack closure plays a significant role. Hammouda et al. [29] attributed the observed short crack growth phenomenon to the combined effect of the notch plasticity and the cracktip plasticity. $\mathrm{Li}$ [30] suggested that the fatigue crack growth from a notch was dominated by notch plasticity within the notch plasticity zone and the notch plasticity induced crack closure out of the notch plasticity zone.

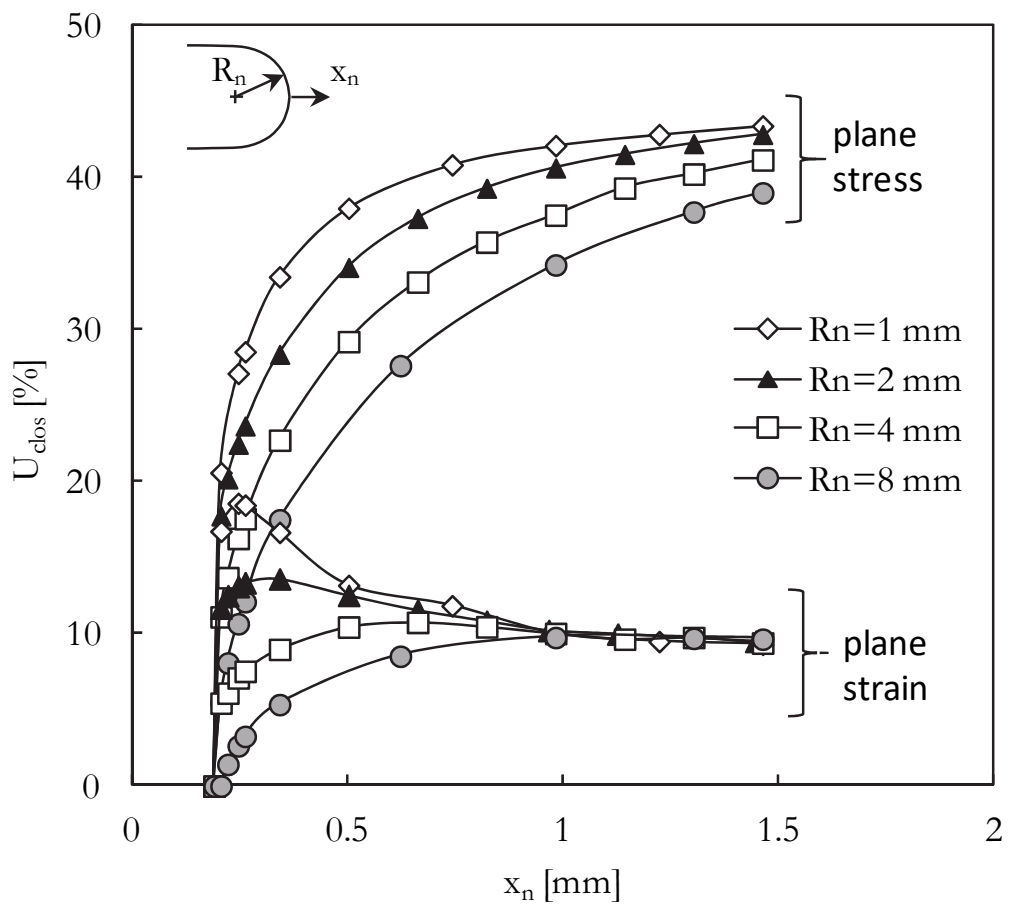

Figure 7: Variation of crack closure with crack length.

\section{Conclusions}

A numerical study was developed to study the effect of notches on fatigue crack growth rate. As the crack propagates, there is an increase of $\delta_{\mathrm{p}}$ and therefore of fatigue crack growth rate. For plane stress state, the reduction of notch radius increases $\delta_{\mathrm{p}}$ for all crack lengths, particularly for the shorter ones. The crack closure level increases with the decrease of notch radius, and this explains the convergence of $\delta_{\mathrm{p}}$ for different notch radius as the crack propagates. For plane strain state there is almost no crack closure, therefore the crack length has a greater impact on plastic CTOD range.

\section{ACKNOWLEDGEMENTS}

7 his research is sponsored by FEDER funds through the program COMPETE (under project T44950814400019113) and by national funds through FCT - Portuguese Foundation for Science and Technology, under the project PTDC/EMS-PRO/1356/2014. One of the authors, P.A. Prates, was supported by a grant for scientific research also from the Portuguese Foundation for Science and Technology (SFRH/BPD/101465/2014). All supports are 
gratefully acknowledged. The authors would also like to thank the DD3IMP in-house code developer team for providing the code and all the support services.

\section{REFERENCES}

[1] Paris, P.C. and Erdogan, J. (1963). Critical analysis of crack growth propagation laws, J. Basic Eng. 85D, pp. 528-534.

[2] Rice, J.R. 1967). Mechanics of crack tip deformation and extension by fatigue, In: Fatigue crack propagation. Philadelphia: ASTM STP 415, pp. 256-271.

[3] Elber, W. (1970). Fatigue crack closure under cyclic tension, Eng. Fract. Mech. 2, pp. 37-45.

[4] Lugo, M. and Daniewicz, S.R. (2011). The influence of T-stress on plasticity induced crack closure under plane strain conditions, Int. J. Fatigue 33, pp.176-185.

[5] Donald, K. and Paris, P.C. (1999). An evaluation of $\Delta \mathrm{K}_{\text {eff }}$ estimation procedure on 6061-T6 and 2024-T3 aluminum alloys, Int J Fatigue 21, pp. S47-57.

[6] Kujawski, D. (2001) Enhanced model of partial crack closure for correlation of R-ratio effects in aluminum alloys, Int J Fatigue 23, pp. 95-102.

[7] Christopher, C.J., James, M.N., Patterson, E.A. and Tee, K.F. (2007). Towards a new model of crack tip stress fields, Int J Fract 148, pp. 361-371.

[8] Antunes, F.V., Sousa, T., Branco, R. and Correia, L. (2015). Effect of crack closure on non-linear crack tip parameters, Int. Journal of Fatigue 71, pp. 53-63.

[9] Kawabata, T., Tagawa, T., Sakimoto, T., Kayamori, Y., Ohata, M., Yamashita, Y., Tamura, E., Yoshinari, H., Aihara, S., Minami, F., Mimura, H. and Hagihara, Y. (2016). Proposal for a new CTOD calculation formula, Eng. Fract. Mech. 159, pp. 16-34.

[10] Laird, C. and Smith, G.C. 1962). Crack propagation in high stress fatigue, Philos. Mag. 8, pp. 847-857.

[11] Toribio, J. and Kharin, V. (2013). Simulations of fatigue crack growth by blunting-re-sharpening: Plasticity induced crack closure vs. alternative controlling variables, Int. J. Fatigue 50, pp. 72-82.

[12] Pelloux, R.M. (1970). Crack Extension by alternating shear, Eng Fract. Mech. 1, pp. 170-174.

[13] Neuber, H. (1961). Theory of stress concentration for shear strained prismatical bodies with arbitrary non-linear stress-strain law. J Appl Mech 28, pp. 544-50.

[14] Molski, K. and Glinka, G. (1981). A method of elastic-plastic stress and strain calculation at a notch root. Mater Sci Eng 50, pp. 93-100.

[15] Lazzarin, P., Berto, F., Gomez, F.J. and Zappalorto, M. (2008). Some advantages derived from the use of the strain energy density over a control volume in fatigue strength assessments of welded joints, Int. J. Fatigue 30, pp. 13451357.

[16] Ellyin, F. (1997) Fatigue Damage, Crack Growth and Life Prediction, Chapman \& Hall, London.

[17] Neuber, H. (1958) Theory of Notch Stresses: Principles for Exact Calculation of Strength with Reference to Structural Form and Material, Springer, Berlin, Germany.

[18] Peterson, R.E. (1958) Notch sensitivity, in: G. Sines, J.L. Waisman (Eds.), Metal Fatigue, McGraw Hill, New York, pp. 293-306.

[19] Susmel, L. and Taylor, D. (2011). The theory of critical distances to estimate lifetime of notched components subjected to variable amplitude uniaxial fatigue loading, Int. J. Fatigue 33, pp. 900-911.

[20] Antunes, F.V., Rodrigues, S.M., Branco, R. and Camas, D. (2016). A numerical analysis of CTOD in constant amplitude fatigue crack growth, Theoretical and Applied Fracture Mechanics 85, pp. 45-55.

[21] Williams, J.C. and Starke, Jr. E.A (2003). Progress in structural materials for aerospace systems, Acta Mater. 51, pp. $5775-5799$.

[22] Wei, L., Pan, Q., Huang, H., Feng, L. and Wang, Y. (2014) Influence of grain structure and crystallographic orientation on fatigue crack propagation behavior of 7050 alloy thick plate, Int Journal of Fatigue 66, pp. 55-64.

[23] Voce, E. (1948). The relationship between stress and strain for homogeneous deformation, J. Inst. Metals 74, pp. $537-562$.

[24] Chaboche, J.L. (2008). A review of some plasticity and viscoplasticity constitutive theories, International Journal of Plasticity 24, pp. 1642-1693.

[25] Miller, K.J. (1982). The short crack problem, Fatigue Engng. Mater. Struct. 5, pp. 223-232.

[26] Tanaka, K., Nakai, Y. (1983). Propagation and non-propagation of short fatigue cracks at a sharp notch, Fatigue Engng. Mater. Struct. 6, pp. 315-327. 
[27] McClung, R.C. and Sehitoglu, H. (1992). Closure and growth of fatigue cracks at notches, J. Engng. Mater. Techn. 114, pp. 1-7.

[28] Ding, F., Feng, M. and Jiang, Y. (2007). Modeling of fatigue crack growth from a notch, International Journal of Plasticity 23, pp. 1167-1188.

[29] Hammouda, M.M., Smith, R.A. and Miller, K.J. (1979). Elastic-plastic fracture mechanics for initiation and propagation of notch fatigue cracks, Fatigue Engng. Mater. Struct. 2, pp. 139-154.

[30] Li, W. (2003). Short fatigue crack propagation and effect of notch plastic field, Nucl. Engng. Des. 84, pp. 193-200. 